\title{
Planning for a resilient urban food system: A case study from Baltimore City, Maryland
}

\section{Erin Biehl a*}

Johns Hopkins Center for a Livable Future, D epartment of Environmental Health

\& Engineering, Johns Hopkins Bloomberg School of Public Health

Sarah Buzogany ${ }^{b}$

Baltimore Food Policy Initiative, Baltimore City Office of Sustainability

\author{
Kristin Baja ${ }^{c}$ \\ Urban Sustainability Directors Network
}

Roni A. Neff $\mathrm{d}$

Johns Hopkins Center for a Livable Future, D epartment of Environmental Health

\& Engineering, Johns Hopkins Bloomberg School of Public Health

Submitted November 21, 2017 / Revised February 13, April 17, and May 8, 2018 / Accepted May 8, 2018 /

Published online October 17, 2018

Citation: Biehl, E., Buzogany, S., Baja, K., \& Neff, R. A. (2018). Planning for a resilient urban food system: A case study from Baltimore City, Maryland. Journal of A griculture, F ood Systems, and C ommunity D evelopment, 8(Suppl. 2), 39-53. https:/ / doi.org/ 10.5304/ jafscd.2018.08B.008

Copyright @ 2018 by the Authors. Published by the Lyson Center for Civic Agriculture and Food Systems. Open access under CC BY license.

\begin{abstract}
Many natural and non-natural hazards threaten food security, especially in urban areas where growing populations place extra demands on the food supply. Ensuring stable food security before, during, and after disasters requires resilient food

a * C orresponding author: Erin Biehl, MSPH, Johns Hopkins Center for a Livable Future, D epartment of Environmental Health \& Engineering, Johns Hopkins Bloomberg School of Public Health; 111 Market Place, Suite 840; Baltimore, Maryland 21202 USA; +1-410-223-1723; ebiehl1@jhu.edu

b Sarah Buzogany, MS, Baltimore Food Policy Initiative, Baltimore City Office of Sustainability; 417 East Fayette Street, 8th Floor; Baltimore, MD 21201 USA;

sarah.buzogany@baltimorecity.gov

c Kristin Baja, MS, CFM, Urban Sustainability Directors Network (https:/ / www.usdn.org); kristinbaja@usdn.org
\end{abstract}

systems that can withstand and recover from disruptions. However, few U.S. cities have considered food systems in disaster preparedness or resilience planning. This reflective case study from the participant-observer perspective examines

d Roni A. Neff, PhD , Johns Hopkins Center for a Livable Future, D epartment of Environmental Health \& Engineering, Johns Hopkins Bloomberg School of Public Health; 111 Market Place, Suite 840; Baltimore, Maryland 21202 USA; rneff1@jhu.edu

\section{Funding Disclosure}

This work was funded by the Johns Hopkins Center for a Livable Future with a gift from the GRACE Communications Foundation, the Johns Hopkins $21^{\text {st }}$ Century Cities Initiative, and the Johns Hopkins Urban Health Institute. The funders had no role in study design, data collection and analysis, preparation of the manuscript, or decision to publish. 
the process and outcomes of a city-university collaboration to assess and begin to improve the resilience of Baltimore City's food system. An academic center and municipal department of planning partnered to assess and plan for shortand long-term food system resilience. An Emergency Food Working Group convened for three meetings over three months, resulting in the creation of an emergency food access protocol for acute event response. A broader Baltimore F ood System Resilience A dvisory Report was then developed based on 36 key-informant interviews with food system stakeholders, literature reviews, and geographic information system (GIS) mapping. That report included an assessment of the Baltimore City food system's vulnerability to hazards, the extent of stakeholder preparedness for food supply disruptions, and identified opportunities for enhancing long-term food system resilience. It presented policy recommendations for Baltimore and a framework for conceptualizing food system vulnerabilities. Policy recommendations and lessons learned from this planning process can serve as an example for other cities interested in enhancing the resilience of their food system or broadening the scope of their resilience planning.

\section{Keywords}

Food System, Resilience, Urban Planning, Climate Change Adaptation, Food Systems Planning, Food Security, Emergency Food Assistance, Food Policy, Case Studies, Northeastern States

\section{Introduction}

\section{Back ground}

Climate change is causing unprecedented shifts in natural systems and threatens global food security (Intergovernmental Panel on Climate Change, 2014). Reduced agricultural productivity, crop damage, disrupted supply chains, and food price spikes are expected to occur more frequently in the coming years (Hatfield et al., 2014). Non-natural hazards such as civil unrest or cyberterrorism also can disrupt food systems. In urban areas, food system disruptions could substantially affect large populations already struggling to access food. Feeding cities despite such challenges requires planning for stable systems that support food security before, during, and after crises. Urban food systems need to become more resilient. This reflective essay presents a participant-observer case study of the authors' collaborative efforts to assess and plan for improved resilience in the food system of one United States city.

Resilience is the capacity to absorb, adapt, and transform in response to a disruption (Béné, Headey, Haddad, \& von G rebmer, 2016). The concept has been applied in diverse fields such as psychology, engineering, and ecology (Fletcher \& Sarkar, 2013; Francis \& Bekera, 2014; Holling, 1973). A resilient food system provides a reliable source of nutritious, safe, accessible food despite disturbances (Candy, Biggs, Larsen, \& Turner, 2015). Most of the initial research on food resilience focused on agricultural resilience (Barthel, Parker, \& Emstson, 2015; James \& Friel, 2015; Koohafkan, Altieri, \& Holt, 2012). Some also focused on supporting food security as one component of disaster recovery or community resilience (Clay, Papas, Gill, \& Abramson, 2018; Links et al., 2018). O ther research focused on more holistically operationalizing food system resilience (Seekell et al., 2017; Tendall et al., 2015; Worstell \& Green, 2017).

There has been relatively little research focused on resilience in food systems supporting urban food security. We reviewed city, county, and regional food system planning documents from 2001 to 2017 and found a small but increasing reference over time to resilience as a planning goal (Biehl, Buzogany, Huang, \& Chodur, 2017). (See, for example, Barron et al., 2010; New Y ork City Economic D evelopment Corporation \& New York City Mayor's Office of Recovery \& Resiliency, 2016; Zeuli \& Nijhuis, 2017; Zeuli, Nijhuis, \& Murphy, 2015.) To our knowledge, no urban food system resilience planning processes are documented in the academic literature.

In this paper, we describe one attempt to improve urban food supply resilience in ways that enhance residents' short- and long-term food security. This reflective case study shares the context, motivation, process, and lessons learned throughout a food resilience planning project in Baltimore City, Maryland. We conceptualize Baltimore City's 
food system as the people, places, and processes involved in ensuring urban food access, availability, and acceptability. We considered ways to improve the preparedness, response, recovery, and adaptability of stakeholders across the system, from farms to processors and distributors, food pantries and stores, and communities. Recognizing that the urban food supply depends on local, regional, national, and global systems, our planning considered not only urban and peri-urban food production, but also food supplied through national and global systems. This reflects the current balance of the urban population's diet and the limitations of urban agriculture as a major food source (Santo, Palmer, \& Kim, 2016). That said, urban planners and policy-makers have influence primarily at the local level. The strategies developed from our efforts consequently focused primarily on supporting resilience in regional food distribution, retailers, and food assistance organizations (such as food pantries). These components currently play a larger role in supporting consistent food security within city limits than do urban farms, seasonal farmers markets, and prepared food sources such as public markets and restaurants.

\section{Baltimore in Contex $\mathrm{t}$}

Located within the Northeast megalopolis, Baltimore City, Maryland, is the 29th largest U.S. city. The population is around 620,000 , of whom $64 \%$ are African American, $30 \%$ are white, and $4 \%$ are Hispanic or Latino (U.S. Census Bureau, 2010). In Baltimore, structural racism is tied to historical policies and planning that led to disenfranchised communities and inequitable access to resources such as healthy food (Bilal, 2016; Misiaszek, Buzogany, \& Freishtat, 2018; Power, 1983). Among Baltimore residents, African Americans disproportionately experience food insecurity, live in healthy food priority areas (formerly called "food deserts"), and have chronic diet-related diseases. Twenty-four percent of city residents are food insecure and $23.5 \%$ live in healthy food priority areas. This means they do not have easy access to healthy, affordable food (Feeding America, 2014; Misiaszek et al., 2018). Twenty-four percent live below the federal poverty line and 25\% receive Supplemental Nutrition Assistance
Program (SNAP) benefits (Feeding America, 2014; U.S. Census Bureau, 2015). As in other urban areas in the U.S. (Companion, 2010), because of high poverty, food pantries and other food assistance programs such as after-school meals play a large role in supporting food security in Baltimore.

For many Baltimore residents, food insecurity is a problem even under everyday circumstances. A disaster could worsen it in the short and long term. Since 2010, severe weather has affected Baltimore with increased intensity (Baja \& G ranberg, 2018; City of Baltimore, 2013). As climate change continues to influence the weather, such events will likely increase in frequency and magnitude in the future. Thus, so will their impacts on Baltimore residents, businesses, infrastructure, and systems.

Baltimore City has a progressive food policy agenda aimed at developing strategies that improve food security and residents' health. It was among the first U.S. cities to designate a city-funded food policy director, a position responsible for leading an initiative based in the Baltimore Department of Planning's O ffice of Sustainability. Since 2010, the Baltimore Food Policy Initiative (BFPI) has led efforts to improve food access across the city. It has expanded its capacity by hiring two additional full-time staff members. For nearly a decade, the O ffice of Sustainability and BFPI have collaborated with the Center for a Livable Future (CLF), an interdisciplinary academic center based within the D epartment of Environmental Health and Engineering at the Johns Hopkins University Bloomberg School of Public Health. The CLF performs research, policy analysis, education, and other activities guided by the perspective that diet, food production, the environment, and public health are interwoven elements of a complex system. Under this collaboration, the CLF and O ffice of Sustainability have co-released several reports that map Baltimore's food, including a metric assessing food healthfulness within stores (Behrens Buczynski, Freishtat, \& Buzogany, 2015; Haering \& Franco, 2010; Misiaszek et al., 2018). The report findings are used to establish policies and initiatives aimed at increasing healthy food access in the city.

Recognizing the threat that climate change poses to food security, the Office of Sustainability 
emphasizes integrating the food system into proactive planning for climate-related hazards. Concurrently, the CLF has expanded its research portfolio to understand and support food system resilience through a public health lens. Lessons learned from this collaboration provide insight for local governments working to incorporate food systems into resilience planning.

\section{Case Study Methods}

The reflective participant-observer case study method used in our research involved an iterative process. We first reviewed documents, notes, and emails shared between collaborators and external partners; we then synthesized that information as well as our event recollection into a narrative and timeline of the planning process (Figure 1). Last, we discussed and shared perceptions of the planning process and distilled experiences into key challenges, successes, and lessons learned from university and municipal planning perspectives. Although the lead author is a university researcher, the narrative was jointly constructed, edited, and reviewed multiple times by both university and city collaborators.

Given that our direct experiences inform this paper, some objectivity may be compromised; however, participant observation provides a rich perspective from which to conduct research. To minimize bias, recollections of events were triangulated with date-stamped documents, emails, and news reports. Non-authors from both institutions who were involved in or observed the planning process reviewed the manuscript and provided feedback.

\section{Planning for Umban Food System Resilience}

Project 0 rigins

Including a food system perspective in the city's disaster preparedness and resilience planning began in 2013. This was the year in which Baltimore became the first city in the U.S. to incorporate food into its all-hazard mitigation plan (Figure 1). Mitigation plans describe risks from and vulnerabilities to natural disasters and design long-term strategies for protecting people and property (Federal Emergency Management Agency, 2017).
Local governments must develop such plans in order to be eligible for federal mitigation planning funding. The Office of Sustainability developed its version, the D isaster Preparedness Project and Plan (DP3), using a unique approach that integrates climate adaptation with hazard mitigation efforts.

An extensive public outreach and engagement process informed an assessment of vulnerable people, places, and resources in the city and led to several components typically not addressed in mitigation planning, including food. D P3 public outreach included over 35 input sessions in the communities that are most vulnerable to natural hazards and that have the highest levels of food insecurity. One component shared one-on-one assistance with residents to develop emergency plans, build emergency kits, and identify assets and shortcomings in their neighborhoods, including in relation to food and water access. These efforts to further engage with residents in vulnerable neighborhoods about food and emergency preparedness continued after the DP3's release.

D uring D P3 development, the O ffice of Sustainability climate resilience planner reached out to Johns Hopkins University to utilize the CLF's food systems expertise. CLF representatives provided input on the plan's "Public Services" section as it related to food. They also began work with the O ffice of Sustainability to identify funds for implementing the D P3 strategy to "Increase Baltimore's Food Security" and "develop a longterm plan for protecting the resilienc[e] of the regional food system" (City of Baltimore, 2013, p. 224). The climate resilience planner also reached out to BFPI for their food policy expertise. Thus, a new collaboration resulted between the CLF, the O ffice of Sustainability climate resilience planner, and BFPI to create a food resilience plan.

Early on, the climate resilience planner led planning efforts, with research support from the CLF and two Johns Hopkins University students. A student team from a course led by CLF faculty and mentored by the climate resilience planner reached out to other cities to understand how past crises affected their food systems. Initial planning and research focused on local food production, including assessing urban agriculture and soil quality. This approach aligns with other early urban 


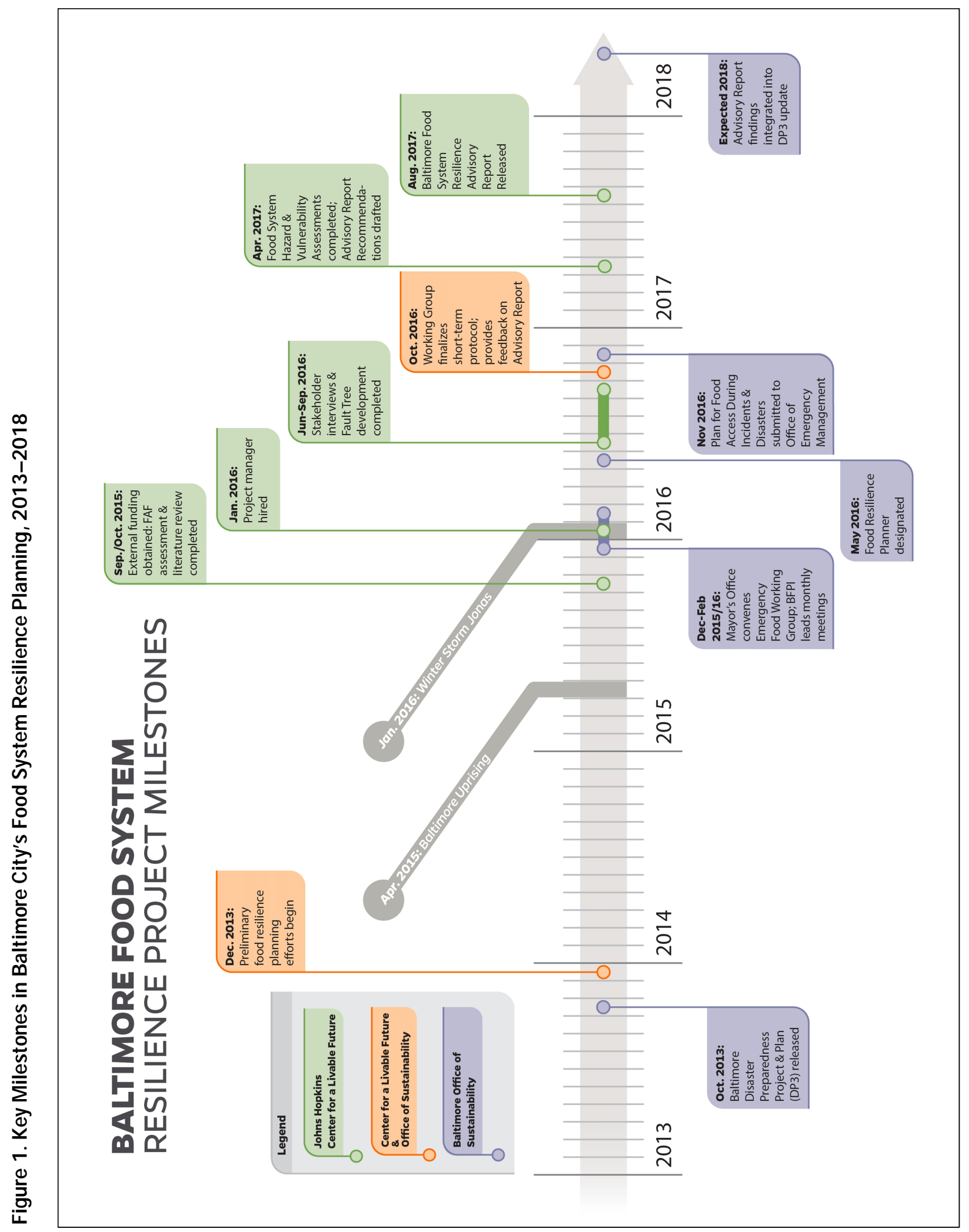


food system resilience work, which focused on food production (Barthel et al., 2015; James \& Friel, 2015). As noted above, however, because of the limits of urban agriculture, the project evolved to emphasize post-farm gate supply chain actors supporting food access and availability for city residents- particularly those who most consistently support food security. These include food assistance organizations, distributors, and retailers critical to the system. Recognizing the need for more sustained financial and human resources to take this approach and support more robust research and planning, the CLF and Office of Sustainability jointly applied for funding.

\section{Short-T erm Food Resilienœ Planning}

The Baltimore U prising. The April 2015 Baltimore Uprising highlighted the ways in which a disruption can harm food security in Baltimore. It also highlighted the need to better coordinate city agencies and food suppliers. Following the death of Freddie $\mathrm{G}$ ray from injuries sustained in police custody, many citizens of Baltimore participated in public demonstrations. Peaceful protests occurred along with civil unrest, including property destruction, arson, and looting. According to the Baltimore D evelopment Corporation, at least 107 food-selling retailers (corner stores, convenience stores, grocery stores, pharmacies, and discount stores) sustained damage to or lost inventory or property (K. D awson, personal communication, April 13, 2017). Approximately $26 \%$ of those stores were located in neighborhoods with already limited access to healthy food. A weeklong night-time curfew also limited food deliveries to stores. Public schools closed for a day, leaving many students without their one regular food source. Many organizations and individuals donated food to Baltimore communities after the unrest; however, local food assistance organizations lacked communication and coordination, creating inefficient donation distribution to residents in need (Maryland Food Bank staff member, personal communication, April 2015).

E mergency response efforts. The Uprising and its impact on the food system motivated the city government to include food in short-term emergency prepared- ness protocols. Traditionally, emergency food providers distribute food with little intervention by city government. The Uprising provided an opportunity to learn where municipal agencies could assist with communication, coordination, and collaboration. As a short-term measure, the O ffice of Sustainability formed an Emergency Food Working Group (herein, the "Working Group") in D ecember 2015. The Working Group included 13 municipal agencies, seven emergency food nonprofits, three state and federal agencies, and the CLF (Figure 2). Members met three times in the winter of 2015-2016 to provide input on the city government's role in supporting private and nonprofit food entities during emergencies. Using this input, the O ffice of Sustainability drafted a Plan for Food Access D uring Incidents and D isasters and shared it with the Working Group in fall 2016. It was then incorporated into the city's Emergency O perations Protocol (EOP) as an appendix to the Mass Care \& Sheltering Emergency Support Function (ESF \#6) and was submitted to the Mayor's O ffice of Emergency Management.

Recognizing the need to incorporate food systems into resilience planning and vice versa, the Office of Sustainability redesignated a food access planner as a "food resilience planner." Along with continuing food resilience planning and implementation, this position now sits in the Emergency $O$ perations Center (EOC) during emergencies and liaises between the EOC and food-providing organizations. Although at the time of writing the O ffice of Sustainability was awaiting administrative approval for the updated EOP, adding food to the protocol, even informally, resulted in more inclusion and support of food system stakeholders during recent events. This was demonstrated when a 2016 blizzard blanketed Baltimore in two and a half feet $(0.76 \mathrm{~m})$ of snow, closing schools for 10 days. With a food liaison in the city's EOC and initial protocols in place, Working Group organizations more effectively coordinated with each other to provide emergency meals to children and seniors.

L ong-term Planning: The Baltimore F ood System Resilience A dvisory Report

Although the short-term Plan for F ood A coess D uring Incidents and D isasters provided needed coordination 
Journal of Agriculture, Food Systems, and Community D evelopment ISSN: 2152-0801 online

https:/ / www.foodsystemsjournal.org

\section{Figure 2. Baltimore's Short-term Plan for Food Access During Incidents and Disasters}

Representatives of government, academia, community, and nonprofit sectors provided input on Baltimore's short-term Plan for Food Access during incidents and disasters. The second ring shows organizations who provided input in the Plan for Food Access. The outer section depicts organizations' responsibilities during and after a crisis.

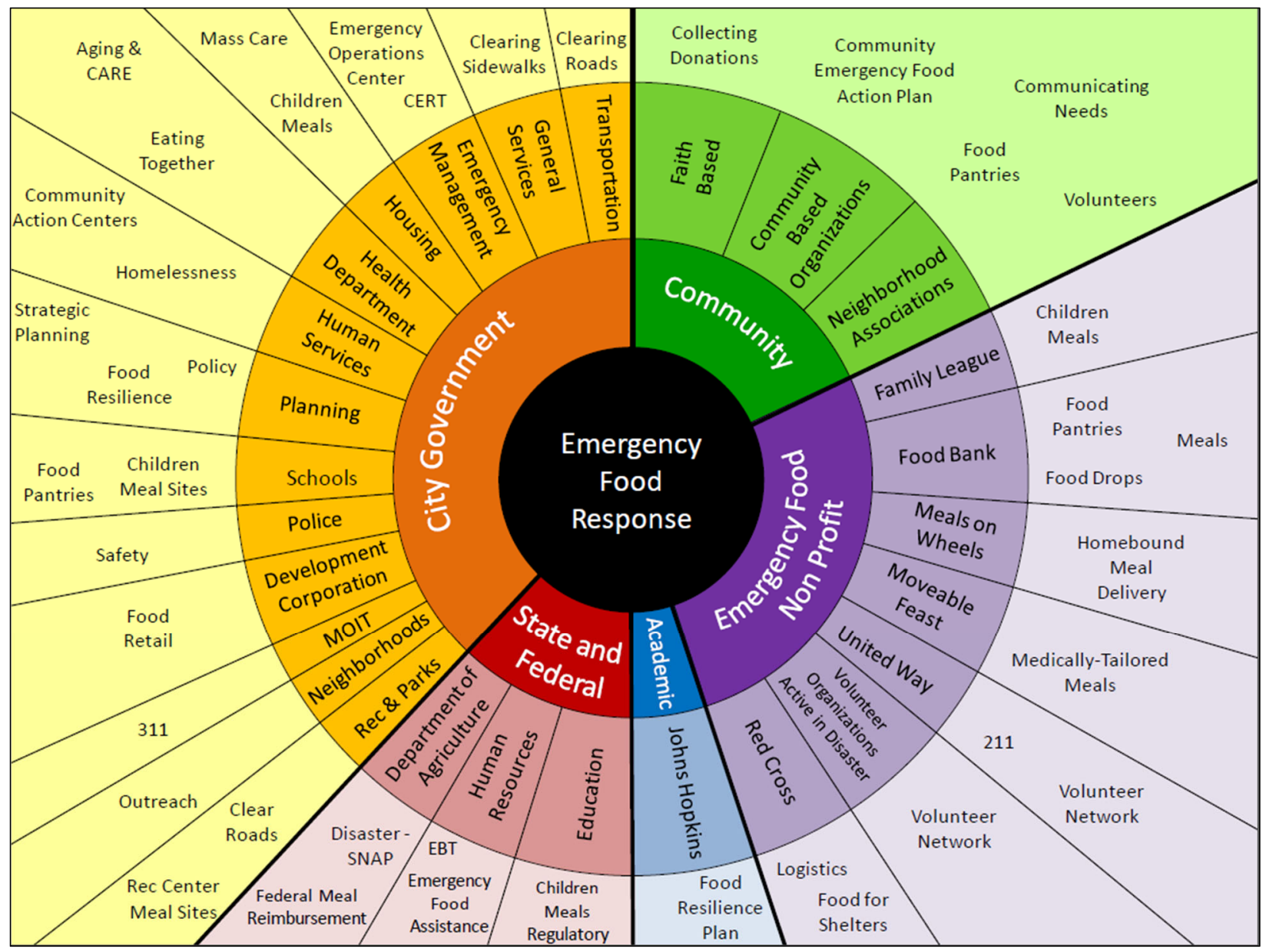

to support food aocess immediately after acute events, the project team recognized a need to support long-term resilience of the food system supplying the city. The CLF led the research and drafting of this resilience assessment, which assessed threats, vulnerabilities, preparedness, and adaptive capabilities across the urban food supply chain. The assessment became the Baltimore $F$ ood System Resilience A dvisory Report (herein, A dvisory Report). The A dvisory Report goes beyond the shortterm Plan for F ood A coess to assess food availability and acceptability. The report also recognizes that the food supplying the city is produced at various geographic scales. The report additionally includes vulnerabilities to non-natural hazards such as electricity failures, unrest, and terrorism.

In the summer following the Uprising, the CLF obtained funding through two Johns Hopkins University initiatives focused either exclusively or in part on improving urban health. They also hired two student research assistants to work on the project. A CLF staff person began serving parttime as a project manager and led research and writing tasks. The project manager and city planners met approximately every month throughout the following year to provide feedback on research progress and to discuss next steps. Although the CLF led report research and writing, the O ffice of Sustainability guided report development to assure that the findings and recommendations were 
framed in a way that the city's urban planners could interpret and use for formal plan development. They also provided input and feedback throughout report development and edited multiple drafts.

Although the initial project goal was to develop a formal "plan" and adopt policies for food resilience in Baltimore, the project goal transitioned into an "advisory report" partway through. It became clear that the research team lacked the capacity to perform the full communityengaged process needed to establish a city plan, and that such engagement was not the university's role. Nevertheless, the report did involve some community input, including in-depth community interviews. The interviews sought input from individuals with broad perspectives and engagement. These individuals generally came from neighborhood associations or were church leaders; however, they did not necessarily live in the communities they represented or experience food insecurity themselves. Therefore, we decided further community engagement was needed before the O ffice of Sustainability and its community partners could adopt and implement the strategies recommended in the report.

The CLF published the A dvisory Report in August 2017 (Biehl et al., 2017), and it became a critical resource the $O$ ffice of Sustainability could use to develop formal planning materials. The Office of Sustainability plans to lead the next phase, which consists of soliciting community input on recommendations and implementing the strategies identified in the report. Those recommendations will be incorporated into policy strategies laid out in the next D P3 update and in other, future planning documents.

The A dvisory Report Research A pproach To withstand and recover from disturbances, food systems must be redundant, flexible, and able to adapt long-term to food security threats (Tendall et al., 2015). A dvisory Report research considered these factors of resilience while following the risk assessment framework utilized in the DP3. The A dvisory Report assesses the current state of and potential threats to the food system supporting Baltimore's food supply; identifies characteristics of food system components and actors that make it more vulnerable to those threats; assesses preparedness among food system actors across the food supply chain; and identifies strategies for reducing vulnerabilities and supporting resilience. To produce the A dvisory Report, the CLF research team reviewed planning and academic literature, interviewed stakeholders in Baltimore's food system, and combined data on the local and regional food system with hazard data to map out vulnerable components of the food system.

L iterature review. We reviewed other jurisdictions' food system plans and emergency preparedness documents and analyzed them for any inclusion and/ or assessment of resilience (Biehl et al., 2017, Appendix A). This review, although not exhaustive, enabled us to selectively capture the progression of food resilience planning from the early 2000s to the present. It also allowed us to learn from other cities.

F ault tree analysis- - A conceptual framework. To provide a new tool for understanding how disruptive events can impact the urban food supply (and consequently food security), the CLF developed a food system fault tree analysis framework (Figure 3) with colleagues in the Johns Hopkins Whiting School of Engineering. Fault tree analysis (FTA) is a valuable tool for planners seeking to conceptualize the range and cascade of threats that could affect a city's food system. When populated with data, it can model hazard and intervention impacts. To develop the tree, we defined a system "failure" as a substantial citywide increase in food insecurity. We used a top-down approach to map out three key components of food security: food accessibility, availability, and acceptability. We identified intermediate events that could lead to these three endpoints (e.g., decreased food availability due to a supply chain failure, due to blocked delivery routes, or due to a basic event such as a snowstorm). Fault trees exist on a continuum; a qualitative determination must define the extent and distribution of loss in access, availability, or acceptability that constitutes food security "failure." Although the fault 
Journal of Agriculture, Food Systems, and Community D evelopment ISSN: 2152-0801 online

https:/ / www.foodsystemsjournal.org

Figure 3. Framework for Conceptualizing Food System Vulnerabilities

Events that lead to inadequate access, availability, or acceptability of food theoretically contribute to increased food insecurity and a food system failure.

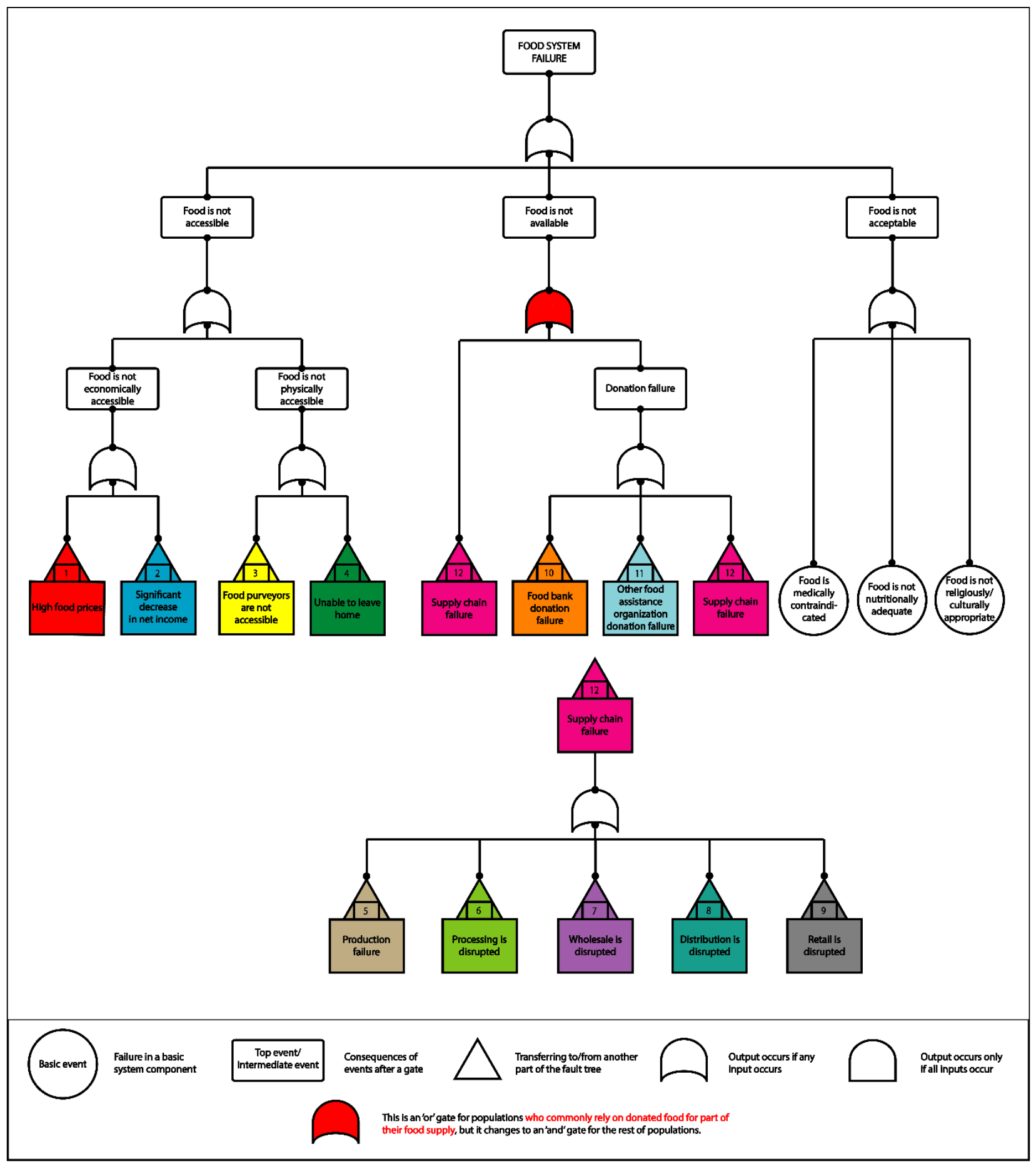

Source: Chodur, Zhao, Biehl, Mitraini-Reiser, \& Neff, 2018. 
tree itself does not measure resilience, it can illustrate system vulnerabilities and risk. Comparing system functioning over time can also help planners understand system resilience and the complexity of food systems.

Stak eholder interviews. CLF researchers performed qualitative interviews with 36 community, nonprofit, business, and government stakeholders who supply, distribute, eat, or improve access to food in Baltimore. The team sought input from CLF and Office of Sustainability networks to identify local and regional actors who had first-hand knowledge of or experience with food system disruptions. The interviews included rich context on how different organizations and individuals experience and prepare for adverse events. Interviews also provided an opportunity for community, nonprofit, and private sector input on planning efforts.

$\mathrm{G}$ eospatial mapping. We created maps identifying neighborhoods and people within city limits who may be most vulnerable to physical hazards like flooding. The CLF had previously developed a Maryland food system map (Johns Hopkins Center for a Livable Future, 2017). We combined data from that map with hazard maps used in the DP3. We identified expected hazard locations in relation to food facilities (stores, warehouses, markets, farms, food pantries, etc.), vulnerable groups (children, older adults, people with disabilities, residents of food deserts), and food distribution routes.

Freight A nalysis Framework. Recognizing that a stable food supply relies on multiple systems as well as infrastructure, we sought to understand how food flows into the city. Student researchers compiled U.S. D epartment of Transportation Federal Highway Administration data from the 2007 Commodity Flow Survey (the most recent data available at that time). With this data, they performed a Freight Analysis Framework (FAF) assessment of the types, value, quantity, and transport mode of foods entering and leaving the Baltimore City Metropolitan Statistical Area (U.S. D epartment of Transportation Federal Highway Administration, 2017).
Stak eholder engagement. Much of the engagement during the development of the A dvisory Report occurred through BFPI's network. BFPI organizes and staffs the Baltimore Food Policy Action Coalition (Food PAC). This coalition links more than 60 members representing nonprofits, institutions, farms, businesses, and residents engaged with the city's food system. Researchers sought input on the A dvisory Report from Food PAC members midway through the project. Participating members helped brainstorm potential hazard impacts and suggested policies or strategies supporting food access and availability during those events. A similar presentation toward the end of the report development shared initial findings and sought the Emergency Food Working Group's input. These meetings informed the report with insights from food system practitioners beyond those interviewed. They also highlighted issues the researchers might not have otherwise considered, such as how changing food assistance benefit policies would affect food access for low-income populations after a disaster. The O ffice of Sustainability also used its annual town hall event to provide hands-on activities, information booths, and opportunities for community member engagement with CLF researchers on food-related concerns before, during, and after disturbances.

\section{Discussion}

Food system resilience is a nascent field for urban planners and researchers alike. All collaborators faced a steep learning curve. By learning from interviews, drawing on our diverse backgrounds, and leveraging resources, we were able to develop a report that sets the stage for a strong effort to increase food system resilience in Baltimore. Further, by working with engineering colleagues focused on disaster resilience, we contributed a novel framework for understanding and addressing resilience and framed chronic food security challenges from a fresh viewpoint. A number of factors contributed to our challenges and successes throughout the planning process. Although our project findings are specific to Baltimore, we share those factors as well as some key lessons learned throughout the process to inform other food system resilience work. 
Factors C ontributing to Sucess

Collaboration. Universities are well positioned to support food system planning efforts and have many resources that can enrich municipal efforts (Whittaker, Clark, SanG iovannni, \& Raja, 2017). Likewise, working with local governments and community leaders provides a pragmatic avenue for research, keeps researchers grounded in their own communities, and connects students with practical experiences. The pre-existing collaboration between the CLF and the Office of Sustainability advanced our ability to work together and helped to establish mutual trust among everyone involved. The informal relationships developed through formal collaboration fostered an understanding of each other's strengths and limitations. This enabled collaborators to efficiently divide tasks. This relationship also enabled the quick translation of research findings into policies and actions; however, the government collaborators would not have had the capacity or resources to conduct this type of robust work on their own.

$D$ ata. Past collaborative projects, such as creating typology and collecting data to characterize local food environments, provided access to extensive datasets that the team repurposed and applied through a resilience lens. Such data enabled us to see, for example, that there are very few food processing facilities and distribution centers located in the city. This led to a recommendation to evaluate processing capacity in the metropolitan area and "expand opportunities for local and regional food aggregation and distribution" (Biehl et al., 2017, p. 123). The readily available data also saved time and enabled A dvisory Report authors to describe the location of and risk to vulnerable and food-insecure populations. These data will provide richer information on food systems to include in the D P3 update and will continue to guide the city's food resilience policy and planning.

0 rganizational and student support. Organizational support and person-power from the $\mathrm{O}$ ffice of Sustainability and the CLF also advanced the work. As described above, the Uprising prompted the local government to devote staff time for food resilience planning and may have provided added relevancy for the CLF to seek funding for followup activities. Foundation funds enabled the CLF to contribute staff and research assistant time, with some in-kind support. Additional in-kind support came from students, who used this project for practicums and classwork.

\section{Challenges}

Community engagement. We aimed for an equitable planning process by purposefully seeking out community leaders for interviews and periodically seeking input from local organizations. Unfortunately, resource and role limitations prevented us from performing the extent of community engagement needed to inform a full and more equitable city plan. However, the concepts behind food system resilience are not well known to the public, and the relevant data had not previously been parsed in this way. Thus, we determined that an overview report could provide the introduction and foundation for engaging with community members and other partners. Including more community members in follow-up planning and policy development could achieve a more equitable approach to planning for food system resilience. D oing so may also uncover new angles on the type of research needed to clarify how best to protect the city's food system and promote food security in the face of a crisis.

D ata limitations. Although the FAF assessment provided some data on the type, origin, and distribution of food entering the city, it did not yield robust results. Limitations included double-counting flows of some food types, a low response rate among businesses surveyed, and the inability to quantify temporal variations in food flow. Getting a more accurate picture requires extensive interviews with food retailers, but this would have constituted a more time-intensive research process than was feasible in our circumstances. Continued work on this topic in Baltimore and elsewhere would benefit from such an in-depth supply chain investigation to complement publicly available commodity flow data. 
Conœptualizing urban food system resilienœ. The "food system resilience" concept is complicated. By definition, it is not feasible to measure resilience prior to an event, and the field has not yet coalesced around established indicators to measure food system resilience. We chose to define food system resilience in terms of how to maintain adequate food supply and access in a city over time with the goal of supporting residents' food security. Because we aimed to inform urban planning policies, however, we limited the scope of in-depth interviews to those who would provide recommendations most relevant to food system actors within Baltimore City. In Baltimore, a city in a colder climate with high poverty rates, we were particularly interested in how to support retail stores and food pantries rather than less commonly frequented, seasonal sources such as farmers markets and community gardens. Although A dvisory Report work included some urban food producers and considered food system components and actors outside city limits (such as regional producers and distribution hubs), further analysis should look more in-depth at those and other components to get a truly systemwide resilience assessment.

D iscussing an abstract state of a complex system can also be challenging. Many conversations with food system stakeholders focused on "emergency preparedness" rather than resilience. Community meetings and engagement opportunities to help identify and interpret what food system resilience means in everyday life would enhance this work. Researchers and policymakers also need clearer language to describe this concept.

\section{Key L essons L earned}

Recognize ongoing food insecurity. Many people live with chronic food insecurity. While disasters can further exacerbate conditions for them, and can increase inequities, resilience planning should never lose sight of this ongoing trauma. Many recommendations in the A dvisory Report focus on lowering existing barriers to food access in already food-insecure communities, even during nondisaster times. They also emphasize that reducing ongoing food insecurity can also strengthen resilience. Seeking input from and including a diverse group of community stakeholders throughout the planning process can help to ensure that solutions take into account the concerns and ideas of those who are most impacted by food insecurity and other crises.

Integrate food systems into other planning efforts. Cities will inevitably experience some emergency that threatens the food supply. That said, not all cities or universities have specific staff or initiatives working on food resilience, nor do they have the resources and established relationships from which we benefitted. Fortunately, there are many ways that food system resilience can be folded into other municipal plans. All municipalities are required to have all-hazards mitigation plans to be eligible for federal predisaster mitigation funding. Planners can add food resilience into such plans, as well as into sustainability plans, comprehensive plans, climate action plans, and urban agriculture plans. Such work offers opportunities to consider food in relation to other systems and infrastructure, community needs assessments, and health impact assessments. Additional opportunities for integrating food resilience into city projects include green infrastructure projects, in which cities can use lots for growing local food-and emergency management initiatives, in which food can be integrated into short-, medium-, and long-term planning, response, and recovery procedures. The work in Baltimore demonstrates one way to integrate food and resilience planning through both short-term and long-term strategies.

C onsider the whole food system. Some research on food system resilience, including our early work, focuses primarily on local food production; however, we argue for a broader conceptualization. Resilience depends on having diverse food sources. In most cities, including Baltimore, local food production and processing are not sufficient to supply adequate food. D eveloping local and regional food production and the supply chains to support it is one way for planners to support food system resilience (D ay-Farnsworth \& Morales, 2011). That said, urban food security depends on an extensive and complex array of processes occurring at many scales and geographies. After the Baltimore Uprising, the importance of understanding and 
supporting food supply chains and access to diverse food sources became even more apparent. Ultimately, the strategies recommended in the A dvisory Report and the Plan for Food A coss support people, places, and infrastructure across the food system supplying Baltimore.

A pply fault tree analysis. This project involved the first known application of FTA to food systems. Office of Sustainability collaborators found it useful for categorizing and communicating potential threats to the city's food supply. The framework can help users visualize which food system components contribute to accessible, available, healthy, and safe food. FTA can also help categorize potential vulnerabilities. We see the fault tree as an entryway to developing a framework for another municipality to assess and minimize vulnerabilities in their food system. As the tool develops, it may provide measurable indicators and enable the modeling of intervention impacts.

\section{Conclusions}

Baltimore was one of the first U.S. cities to plan for a more resilient food system supporting its population. This work was strengthened by a longstanding collaboration between an academic center and a municipal planning department. This collaboration and resulting strategies serve as a model to inform how other cities can pursue food system resilience planning in ways that consider a food system's complexity. Although hazards, vulnerabilities, and food system components vary from city to city, the basic methods and framework used to assess Baltimore's food system can be adapted and applied to other jurisdictions. As demonstrated in Baltimore, taking proactive action to address and anticipate a food system's weak points can provide immediate benefits to urban populations while also reducing potential impacts from future events that threaten global and local food supplies. As climate change, population growth, and urbanization pose new challenges for urban areas around the world, adopting proactive and comprehensive strategies for improving food system resilience can help to ensure that everyone has healthy food to eat now and in the future.

\section{Acknowledgments}

We thank Alice Huang and Holly Freishtat (Baltimore O ffice of Sustainability) for their project contributions; Holly Freishtat (Baltimore Office of Sustainability), Anne Palmer, Shawn MacKenzie, and James Yager (CLF) for manuscript review; and Gwen Chodur, Xilei Zhao, and Judith MitraniReiser for co-development of the fault tree framework.

\section{References}

Baja, K., \& G ranberg, M. (2018). From engagement to empowerment: Climate change and resilience planning in Baltimore City. In S. Maloney, H. Fünfgeld, \& M. G ranberg (Eds.), L ocal action on climate change: 0 pportunities and constraints (1st ed., pp. 126-145). New York: Routledge.

Barron, M., G oldblatt, B., Ho, C., Hudson, R., Kaplan, D ., Naumoff, C.,... Wilson, M. (2010). U nderstanding N ew Y ork City's food supply. Retrieved from http:/ / mpaenvironment.ei.columbia.edu/ files/ 2014/ 06/ UnderstandingNYCsFoodSupply May2010.pdf

Barthel, S., Parker, J., \& Ernstson, H. (2015). Food and green space in cities: A resilience lens on gardens and urban environmental movements. U rban Studies, 52(7), 1321-1338. https:/ / doi.org/ 10.1177/ 0042098012472744

Behrens Buczynski, A., Freishtat, H., \& Buzogany, S. (2015). M apping Baltimore City's food environment: 2015 report. Retrieved from https:// www.jhsph.edu/ research/ centers-and-institutes/johns-hopkins-center-for-a-livablefuture/ research/clf_publications/ pub rep_desc/ mapping-baltimore-city-food-environment.html

Béné, C., Headey, D ., Haddad, L., \& von G rebmer, K. (2016). Is resilience a useful concept in the context of food security and nutrition programmes? Some conceptual and practical considerations. Food Seaurity, 8(1), 123-138. https:// doi.org/ 10.1007/ s12571-015-0526-x

Biehl, E., Buzogany, S., Huang, A., Chodur, G ., \& Neff, R. (2017). Baltimore F ood System Resilience A dvisory Report. Retrieved from https:/ / www.jhsph.edu/ research/ centers-and-institutes/johns-hopkins-center-for-a-livablefuture/_pdf/ projects/ resilience/ Baltimore-Resilience-Report.pdf 
Bilal, U. (2016, July 8). The long shadow of redlining on the food system [Blog post]. Retrieved from http:/ / livablefutureblog.com/2016/ 07/ redlining-food-system

Candy, S., Biggs, C., Larsen, K., \& Turner, G. (2015). Modelling food system resilience: A scenario-based simulation modelling approach to explore future shocks and adaptations in the Australian food system. Journal of E nvironmental Studies and Sciences, 5(4), 712- 731. https:// doi.org/ 10.1007/ s13412-015-0338-5

Chodur, G., Zhao, X., Biehl, E., Mitrani-Reiser, J., \& Neff, R. (2018). Assessing food system vulnerabilities: A fault tree modeling approach. BM C Public H ealth, 18, 817. https:/ / doi.org/ 10.1186/ s12889-018-5563-x

City of Baltimore. (2013). D isaster Preparedness and Planning Project: A combined all hazards mitigation and dimate adaptation plan. Retrieved from https:/ / www.baltimoresustainability.org/ wp-content/ uploads/ 2015/ 12/ Executivesummary.pdf

Clay, L. A., Papas, M. A., G ill, K., \& Abramson, D . M. (2018). Application of a theoretical model toward understanding continued food insecurity post Hurricane Katrina. D isaster M edicine and Public $\mathrm{H}$ ealth Preparedness, 12(1), 47-56. https:// doi.org/ 10.1017/ dmp.2017.35

Companion, M. (2010). Constriction in the variety of urban food pantry donations by private individuals. Journal of U rban A ffairs, 32(5), 633-646. https:/ / doi.org/ 10.1111/ j.1467-9906.2010.00511.x

Day-Farnsworth, L., \& Morales, A. (2011). Satiating the demand: Planning for alternative models of regional food distribution. Journal of A grialture, Food Systems, and Community D evelopment, 2(1), 227-247. https:// doi.org/ 10.5304/jafscd.2011.021.020

Federal Emergency Management Agency. (2017). Hazard mitigation planning. Retrieved O ctober 30, 2017, from https:// www.fema.gov/ hazard-mitigation-planning

Feeding America. (2014). Food insecurity in Baltimore city County. Retrieved January 29, 2017, from http:/ / map.feedingamerica.org/ county/ 2014/ overall/ maryland/ county/ baltimore-city

Fletcher, D ., \& Sarkar, M. (2013). Psychological resilience: A review and critique of definitions, concepts, and theory. E uropean Psychologist, 18, 12-23. https:/ / doi.org/ 10.1027/ 1016-9040/ a000124

Francis, R., \& Bekera, B. (2014). A metric and frameworks for resilience analysis of engineered and infrastructure systems. Reliability E ngineering and System Safety, 121, 90-103. https:/ / doi.org/ 10.1016/ j.ress.2013.07.004

Haering, S. A., \& Franco, M. (Eds.). (2010). The Baltimore City food environment. Retrieved from https:// www.jhsph.edu/ research/ centers-and-institutes/johns-hopkins-center-for-a-livablefuture/_pdf/ research/clf_reports/ BaltimoreCityFoodEnvironment.pdf

Hatfield, J., Takle, G., G rotjahn, R., Holden, P., Izaurralde, R. C., Mader, T.,... Liverman, D . (2014). Agriculture. In J. M. Melillo, T. C. Richmond, \& G. W. Y ohe (Eds.), Climate change impacts in the U nited States: The Third N ational Climate A ssessment (pp. 150-174). https:/ / doi.org/ 10.7930/ J0Z31WJ2

Holling, C. S. (1973). Resilience and stability of ecological systems. A nnual Review of E oology and Systematics, 4, 1-23. https:/ / doi.org/ 10.1146/ annurev.es.04.110173.000245

Intergovernmental Panel on Climate Change. (2014). Climate change 2014: Synthesis report summary chapter for policymak ers. Retrieved from https:// www.ipcc.ch/pdf/ assessment-report/ ar5/ syr/AR5 SYR_FINAL_SPM.pdf

James, S. W., \& Friel, S. (2015). An integrated approach to identifying and characterising resilient urban food systems to promote population health in a changing climate. Public $\mathrm{H}$ ealth $\mathrm{N}$ utrition, 18(13), 2498-2508. https:// doi.org/ 10.1017/ S1368980015000610

Johns Hopkins Center for a Livable Future. (2017). Maryland food system map. Retrieved November 13, 2017, from http:// mdfoodsystemmap.org/

Koohafkan, P., Altieri, M. A., \& Holt G imenez, E. (2012). G reen agriculture: Foundations for biodiverse, resilient and productive agricultural systems. International Journal of A gricultural Sustainability, 10(1), 61-75. https:// doi.org/ 10.1080/ 14735903.2011.610206

Links, J. M., Schwartz, B. S., Lin, S., Kanarek, N., Mitrani-Reiser, J., Sell, T. K., ... Kendra, J. M. (2018). CO PEWELL: A Conceptual framework and system dynamics model for predicting community functioning and resilience after disasters. D isaster M edicine and Public H ealth Preparedness, 12(1) 127-137. https:/ / doi.org/ 10.1017/ dmp.2017.39 
Misiaszek, C., Buzogany, S., \& Freishtat, H. (2018). Baltimore City's food environment: 2018 report. Retrieved from https:/ / www.jhsph.edu/ research/ centers-and-institutes/ johns-hopkins-center-for-a-livablefuture/ research/clf publications/ pub rep desc/ baltimore-city-food-environment-report2018.html

New York City Economic D evelopment Corporation, \& New Y ork City Mayor's O ffice of Recovery \& Resiliency. (2016). Five borough food flow: $2016 \mathrm{~N}$ ew Y ork City food distribution \& resiliency study results. Retrieved from https:/ / www.nycedc.com/ system/ files/ files/ resource/ 2016 food_supply-resiliency_study_results.pdf

Power, G . (1983). A partheid Baltimore style: The residential segregation ordinances of 1910-1913. M aryland L aw Review, 42, 289-328. Retrieved from https:/ digitalcommons.law.umaryland.edu/ fac pubs/ 184

Santo, R., Palmer, A., \& Kim, B. (2016). V acant lots to vibrant plots: A review of the benefits and limitations of urban agrialture. Retrieved from https:// www.jhsph.edu/ research/ centers-and-institutes/ johns-hopkins-center-for-a-livablefuture/ $\mathrm{pdf} /$ research/clf reports/ urban-ag-literature-review.pdf

Seekell, D ., Carr, J., Dell'Angelo, J., D ’O dorico, P., Fader, M., G ephart, J.,... Tavoni, A. (2017). Resilience in the global food system. E nvironmental Research L etters, 12(2). https:/ / doi.org/ 10.1088/ 1748-9326/ aa5730

Tendall, D. M., Joerin, J., Kopainsky, B., Edwards, P., Shreck, A., Le, Q. B., ... Six, J. (2015). Food system resilience: D efining the concept. G lobal F ood Seaurity, 6, 17-23. https:/ / doi.org/ 10.1016/ j.gfs.2015.08.001

U.S. Census Bureau. (2010). Community Facts: Baltimore City, M aryland. Profile of general population and housing characteristics: 2010 [Table]. Retrieved from https:// factfinder.census.gov

U.S. Census Bureau. (2015). 2011-2015 American Community Survey 5-year estimates. Retrieved from https:// www.census.gov/ programs-surveys/ acs/ technical-documentation/ table-and-geography-changes/ 2015/ 5year.html

U.S. D epartment of Transportation Federal Highway Administration. (2017). Freight Analysis Framework. Retrieved from https:// ops.fhwa.dot.gov/ freight/ freight analysis/ faf/

Whittaker, J. R., Clark, J. K., SanG iovannni, S., \& Raja, S. (2017). Planning for food systems: Community-university partnerships for food-systems transformation. M etropolitan U niversities, 28(1), 7-26. https:/ / doi.org/ 10.18060/ 21471

Worstell, J., \& Green, J. (2017). Eight qualities of resilient food systems: Toward a sustainability/ resilience index. Journal of A griculture, F ood Systems, and Community D evelopment, 7(3), 23-41. https:/ / doi.org/ 10.5304/ jafscd.2017.073.001

Zeuli, K., \& Nijhuis, A. (2017). The resilience of A merica' s urban food systems: E videnœ from five cities. Retrieved from http:/ / icic.org/ wp-content/ uploads/ 2017/ 01/ Rockefeller_ResilientFoodSystems_FINAL_post.pdf?x96880

Zeuli, K., Nijhuis, A., \& Murphy, P. (2015). Resilient food systems, resilient cities: Recommendations for the City of Boston. Retrieved from http:// icic.org/ wp-content/ uploads/2016/04/ ICIC_Food_Systems final revised post.pdf 